Defraeye T., Verboven P., Opara U.L., Nicolai B., Cronjé P. (2015), Feasibility of ambient loading of citrus fruit into refrigerated containers for cooling during marine transport, Biosystems Engineering 134, 20-30. http://dx.doi.org/10.1016/j.biosystemseng.2015.03.012

\title{
Feasibility of ambient loading of citrus fruit into refrigerated containers for cooling during marine transport
}

Thijs Defraeye ${ }^{a, b, c *}$, Pieter Verboven ${ }^{c}$, Umezuruike Linus Opara ${ }^{d, e}$, Bart Nicolai ${ }^{c, f}$, Paul Cronjé ${ }^{g}$

a Laboratory for Building Science and Technology, Swiss Federal Laboratories for Materials Testing and Research (Empa), Überlandstrasse 129, 8600 Dübendorf, Switzerland

${ }^{b}$ Chair of Building Physics, Swiss Federal Institute of Technology Zurich (ETHZ), Stefano-FransciniPlatz 5, 8093 Zürich, Switzerland

${ }^{c}$ MeBioS, Department of Biosystems, KU Leuven, Willem de Croylaan 42, 3001 Heverlee, Belgium

${ }^{d}$ South African Research Chair in Postharvest Technology, Department of Horticultural Sciences, Stellenbosch University, Stellenbosch 7602, South Africa

e South African Research Chair in Postharvest Technology, Department of Food Science, Stellenbosch University, Stellenbosch 7602, South Africa

${ }^{f}$ VCBT, Flanders Centre of Postharvest Technology, Willem de Croylaan 42, 3001 Heverlee, Belgium

${ }^{g}$ Citrus Research International, Department of Horticultural Sciences, Stellenbosch University,

Stellenbosch 7602, South Africa

\section{$\underline{\text { Keywords }}$}

refrigerated container, cold chain, packaging, oranges, precooling, export

\footnotetext{
* Corresponding author. Tel.: tel. +41 (0)58 7654790.

E-mail address: defraeye@arch.ethz.ch
} 
Defraeye T., Verboven P., Opara U.L., Nicolai B., Cronjé P. (2015), Feasibility of ambient loading of citrus fruit into refrigerated containers for cooling during marine transport, Biosystems Engineering 134, 20-30. http://dx.doi.org/10.1016/j.biosystemseng.2015.03.012

\section{Abstract}

As an alternative to forced-air precooling, warm loading of citrus fruit into refrigerated containers for cooling during marine transport was explored. This practice could provide several logistic and economic savings. Although successful for resilient citrus fruits, the cooling process and performance of ambient loading have not been explored in a systematic manner. There is still a considerable potential to optimise the implementation of the technique and to apply it to more sensitive citrus or other fruits. Calculations identified the required cooling capacity of a refrigerated container as a function of the envisaged fruit cooling time, and these were complemented by a full-scale experiment. Although a refrigerated container was theoretically able to cool the produce in less than 5 days, the experiment showed that these cooling rates are not currently achieved in practice, bearing in mind that step-down cooling was applied. Future improvements in the technique point towards an improved box design and better stacking on the pallet, and to reducing airflow shortcircuits between pallets. 
Defraeye T., Verboven P., Opara U.L., Nicolai B., Cronjé P. (2015), Feasibility of ambient loading of citrus fruit into refrigerated containers for cooling during marine transport, Biosystems Engineering 134, 20-30. http://dx.doi.org/10.1016/j.biosystemseng.2015.03.012

\section{Nomenclature}

$\begin{array}{ll}C_{a v g} & \text { average chilling injury index for an entire box, [-] } \\ c_{p} & \text { specific heat capacity of the oranges, }\left[\mathrm{J} \mathrm{kg}^{-1} \mathrm{~K}^{-1}\right] \\ m & \text { total mass of oranges in the container, }[\mathrm{kg}] \\ P_{A V G, 7 / 8,5} & \text { average refrigeration power for the simplified method, [W] } \\ P_{A V G, 7 / 8, d} & \text { average refrigeration power for the detailed method, [W] } \\ P_{\text {peak, }} & \text { peak power, [W] } \\ R_{0} & \left.\text { momentary cooling rate at the start of cooling, [ }{ }^{\circ} \mathrm{C} \mathrm{h}{ }^{-1}\right] \\ t_{7 / 8} & \text { seven-eighths cooling time, [s] or [h] } \\ t_{1 / 2} & \text { half cooling time, [s] or [h] } \\ T_{\text {ini }} & \text { initial temperature of the oranges, }\left[{ }^{\circ} \mathrm{C}\right] \\ T_{\text {air }} & \left.\text { cooling air temperature, [ }{ }^{\circ} \mathrm{C}\right] \\ T_{7 / 8} & \end{array}$


Defraeye T., Verboven P., Opara U.L., Nicolai B., Cronjé P. (2015), Feasibility of ambient loading of citrus fruit into refrigerated containers for cooling during marine transport, Biosystems Engineering 134, 20-30. http://dx.doi.org/10.1016/j.biosystemseng.2015.03.012

\section{Introduction}

The worldwide exports of fruits and vegetables exceeded 150 billion \$US in 2010 (FAO, 2013). A common method for the handling of fresh produce - such as citrus fruit - for export is transport from pack houses using pallets to forced-air precooling facilities either inland or at the harbour, where precooling of the produce takes place. This is followed by overseas export in bulk refrigerated vessels (reefer vessels) or in refrigerated containers (reefer containers). In this fresh-produce cold chain, the rapid removal of the field heat after harvest and packing is essential since postharvest quality and shelf-life are strongly affected by the temperature history of the produce. Forced-air precooling (FAC) is the most commonly used technique for this purpose (Dehghannya, Ngadi, \& Vigneault, 2010). Particular disadvantages with FAC are the additional time and cost required to handle the pallets and precool the fruit at these facilities, and the delayed start of the cold chain process due to the often lengthy unrefrigerated transport to the precooling facility. The cold chain is often delayed further if the capacity of the precooling facilities is limited and a backlog occurs. Such problems are encountered, amongst others, in the South African citrus industry which exported 1.5 million t during the 2013 season making it the third largest exporter of fresh citrus fruit worldwide (CGA, 2013).

The pressure on the South African FAC facilities will increase in the future as more export markets for all citrus cultivars demand a cold disinfestation treatment as a risk mitigation method for pests that may be associated with the fruit export pathway. Cold disinfestation protocols imply that citrus fruit have to be precooled, prior to loading, to lower temperatures (between -0.5 and $2{ }^{\circ} \mathrm{C}$, depending on the export market) than those applied for normal precooling (between 4 and $7^{\circ} \mathrm{C}$, e.g. (Thompson, 2003)). Subsequently, the fruit have to be kept several weeks at this temperature during overseas transport. Such methods are requested to disinfest the fruit from pests such as fruit fly (Ceratitis capitata and C. rosa) or the false codling moth (Thaumatotibia leucotreta), the latter being a pest that is typical for South Africa. However, not only is the development of chilling injuries 
Defraeye T., Verboven P., Opara U.L., Nicolai B., Cronjé P. (2015), Feasibility of ambient loading of citrus fruit into refrigerated containers for cooling during marine transport, Biosystems Engineering 134, 20-30. http://dx.doi.org/10.1016/j.biosystemseng.2015.03.012

enhanced by these low temperatures but there is an associated longer precooling time $(\approx 72 \mathrm{~h})$. The increasing volumes of fruit exported from South Africa to cold disinfestation markets will soon outpace the current capacity of the precooling facilities.

To mitigate such problems, particularly since FAC facilities are not always available in developing countries, an alternative cold-chain strategy, which is referred to in South Africa as "ambient loading" or "warm loading", is sometimes applied for less-sensitive citrus fruit and for banana (Jedermann, Geyer, Praeger, \& Lang, 2013; Jedermann, Praeger, Geyer, \& Lang, 2014). This practice implies that fruit are loaded warm (i.e. not precooled) into a refrigerated container at the pack house or at the harbour, after which they are cooled during marine transport (Heap, 2006; J. F. Thompson, 2004). However, in order for the fruit to be loaded at ambient conditions, a set of regulations must be followed (PPECB, 2013). Currently only Valencia orange, lemon or grapefruit are allowed to be shipped this way from South Africa. If the pulp temperature of the fruit in a pallet is found to be above $22^{\circ} \mathrm{C}$, the pallet cannot be loaded but must undergo precooling. For South African citrus fruit which are not destined for cold disinfestation markets $\left(4-7^{\circ} \mathrm{C}\right.$ pulp temperature during transport), ambient loading is applied sometimes. This practice provides a shorter cold chain and less handling of fruit as the loaded container can be moved directly from the pack house into the ship, instead of having to pass through the precooling facility.

Current ambient loading technology, however, faces some limitations. Although it is successfully used for resilient citrus cultivars, e.g., sweet orange, it is less promising for more sensitive (decay and disorder prone) cultivars such as mandarins. In addition, this practice has been left largely unexplored for other, more perishable fruit species. Currently, this practice cannot be applied for fruit destined for cold disinfestation treatments due to the inherent lower temperatures and the faster cooling rate required to meet the strict regulatory criteria. Finally, the method has been developed by trial-and-error in the industry. Although to date, the method has yielded acceptable performance, it has not yet been optimised with respect to cooling, which is the single most 
Defraeye T., Verboven P., Opara U.L., Nicolai B., Cronjé P. (2015), Feasibility of ambient loading of citrus fruit into refrigerated containers for cooling during marine transport, Biosystems Engineering 134, 20-30. http://dx.doi.org/10.1016/j.biosystemseng.2015.03.012

important aspect determining quality, shelf-life and associated food losses. In fact, little is known in general about the actual cooling process inside reefer containers (or refrigerated trucks) during transport. Associated experimental or numerical studies have been rather limited (Hoang, Laguerre, Moureh, \& Flick, 2012; James, James, \& Evans, 2006; Jedermann et al., 2013, 2014; Jiménez-Ariza et al., 2014; Moureh \& Flick, 2004; Moureh, Menia, \& Flick, 2002; Moureh, Tapsoba, Derens, \& Flick, 2009; Rodríguez-Bermejo, Barreiro, Robla, \& Ruiz-García, 2007; Tanner \& Amos, 2003; Tapsoba, Moureh, \& Flick, 2006, 2007). This research mainly focussed on airflow/temperature distributions and uniformity instead of product cooling rate. A limited amount of research on reefer containers has been carried out, which is rather surprising since this way of overseas transport has outpaced shipping in bulk reefer vessels over the past decade (Arduino, Carrillo Murillo, \& Parola, 2013; Fitzgerald, Howitt, Smith, \& Hume, 2011). During the 2013 season, only $18 \%$ of the 1.4 million pallets of exported South African citrus fruit were shipped in conventional bulk reefer vessels, which highlights the need to better understand the cooling process and temperature control in a refrigerated container. However, for FAC and refrigerated storage applications, much more numerical and experimental research has been reported (e.g. (Ambaw et al., 2013; Dehghannya et al., 2010; Delele et al., 2008, 2009; Ferrua \& Singh, 2009; Nahor, Hoang, Verboven, Baelmans, \& Nicolaï, 2005; Pathare, Opara, Vigneault, Delele, \& Al-Said, 2012)).

Ambient loading is very challenging as it differs in many aspects from normal FAC (Fig. 1 and Table 1). Firstly, airflow rates and the installed cooling capacity are much lower, since reefer containers are designed to only keep the fruit cool and to limit moisture losses (Thompson, Mitchell, Rumsey, Kasmire, \& Crisosto, 2008). Despite this lower cooling capacity, Jedermann et al. (2014) found that for bananas packed in polyethylene bags in cardboard boxes the limiting factor for the fruit cooling rate was the amount of heat that can be removed from the fruit by airflow through the boxes, and not the cooling capacity of the reefer container. This indicated that the cooling capacity of the refrigeration unit was not fully utilised. Furthermore, airflow is vertical and not horizontal, as in FAC, 
Defraeye T., Verboven P., Opara U.L., Nicolai B., Cronjé P. (2015), Feasibility of ambient loading of citrus fruit into refrigerated containers for cooling during marine transport, Biosystems Engineering 134, 20-30. http://dx.doi.org/10.1016/j.biosystemseng.2015.03.012

which implies a longer pathway for air, resulting in slower cooling of fruit in the upper boxes. Also, box design and stacking on the pallet are not optimised for vertical flow and wooden pallet bases can also block a significant amount of airflow through vent holes. The airflow distribution over the different pallets through the container T-bar floor is also probably less uniform as in most precooling facilities. Finally, closing air short-circuits between pallets, which is a major influence factor on the performance of FAC (Fraser \& Eng, 1998), is less straightforward in a reefer container due to limited access to these short-circuits (Thompson, 2004).

For this underexplored ambient loading method of cooling, a more systematic evaluation is required to enable further implementation for citrus and other fruit species, to further improve product shelflife and to reduce food losses. In this study, the feasibility of ambient loading of citrus fruit was evaluated in two ways within the context of cold disinfestation treatment. Firstly, calculations were performed to identify the cooling time which could be theoretically achieved with the typical cooling capacity that is installed in a state-of-the-art reefer container. Secondly, a full-scale experiment was performed in a reefer container to evaluate how rapidly fruits can be cooled down in practice. Next to verifying the feasibility, future perspectives towards improvement of the technique are discussed.

\section{Materials and methods}

\subsection{Reefer container and citrus fruit}

A state-of-the-art reefer container was used in the present study; namely a Maersk 40 foot Mark $Q$ container, equipped with a Starcool refrigeration unit (Maersk, 2014). The container $(12.2 \times 2.4 \times 2.9$ m) was filled with 20 pallets (Fig. 2). On each pallet, 8 layers of boxes were stacked. Each layer held 10 Supervent corrugated fibreboard boxes $(0.4 \times 0.3 \times 0.27 \mathrm{~m})$, which were filled with oranges $\mathrm{cv}$. Navel (125 fruit per box with a calibre 5, i.e. a diameter between $62-65 \mathrm{~mm}, 16.5 \mathrm{~kg}$ per box). 
Defraeye T., Verboven P., Opara U.L., Nicolai B., Cronjé P. (2015), Feasibility of ambient loading of citrus fruit into refrigerated containers for cooling during marine transport, Biosystems Engineering 134, 20-30. http://dx.doi.org/10.1016/j.biosystemseng.2015.03.012

\subsection{Calculation of required cooling capacity}

Based on the detailed specifications of the Maersk container, the Starcool refrigeration unit and the amount of orange fruit inside, the required cooling capacity of the refrigeration unit was calculated as a function of the envisaged fruit cooling time. To this end, calculation methods used for FAC were used but within the new setting of a reefer container.

The seven-eighths cooling time $\left(\mathrm{SECT}, t_{7 / 8}\right)$ was chosen as the envisaged cooling time, which is the time required to reduce the temperature difference between the fruit and the cooling air by seveneighths. The SECT is frequently applied in commercial FAC operations since at that moment the fruit temperature is acceptably close to the required storage temperature, and the remaining heat load can be removed with less energy costs (Brosnan \& Sun, 2001). As reaching the final set temperature will take much longer $\left(t_{\text {end }} \gg>>t_{7 / 8}\right)$ due to the exponential nature of the cooling curve (Thompson et al., 2008), the SECT is a more representative quantity and hence was applied in the present study as well. This SECT is dependent on the size, shape and thermal properties of the fruit but also on the airflow rate and the accessibility of the airflow to the fruit. The latter is determined not only by the fruit stacking pattern in the boxes, the design of the packaging (i.e., location of vent holes and total vent area) but also by the stacking of individual boxes on a pallet, as vent holes might be closed or airflow can bypass the fruit through openings that occur between individual boxes or pallets (Defraeye et al., 2014). The SECT can therefore be considered a characteristic of the system. It was considered as a variable parameter in the calculations as it is unknown.

A first estimate of the required cooling power was obtained from the average cooling load, i.e. the time-average of the amount of heat to be cooled away until the SECT is reached $\left(P_{A V G, 7 / 8}[\mathrm{~W}]\right)$. This $P_{A V G, 7 / 8}$ was calculated in two ways. Firstly, in a simplified way, only the product heat load was accounted for, thus assuming no additional heat sources or losses. The average refrigeration power required $\left(P_{A V G, 7 / 8,5}[\mathrm{~W}]\right)$ can then be written as a function of the SECT: 
Defraeye T., Verboven P., Opara U.L., Nicolai B., Cronjé P. (2015), Feasibility of ambient loading of citrus fruit into refrigerated containers for cooling during marine transport, Biosystems Engineering 134, 20-30. http://dx.doi.org/10.1016/j.biosystemseng.2015.03.012

$P_{A V G, 7 / 8, s}=\frac{m c_{p}\left(T_{i n i}-T_{7 / 8}\right)}{t_{7 / 8}}$

where $m$ is the total mass of oranges in the container (26 $400 \mathrm{~kg}$ : 20 pallets of 80 cartons weighing on average $16.5 \mathrm{~kg}$ each) and $c_{p}$ is the specific heat capacity of the oranges (taken as $3850 \mathrm{~J} \mathrm{~kg}^{-1} \mathrm{~K}^{-1}$ ). The initial temperature of the oranges $\left(T_{i n i}\right)$ was taken as $20^{\circ} \mathrm{C}$ and the set temperature was assumed equal to the cooling air temperature $\left(T_{\text {air }}\right)$ and was taken as $-1.5^{\circ} \mathrm{C}$, as representative for current cold disinfestation treatment practice. This set temperature has to be lower than the envisaged fruit temperature (between -0.5 and $2{ }^{\circ} \mathrm{C}$ for cold disinfestation, depending on the export market) to reach the latter within an acceptable timeframe, but it cannot be too low because excessive chilling (or freezing) injury may occur. The resulting temperature at SECT (i.e., $T_{7 / 8}=T\left(t_{7 / 8}\right)$ ) was $1.2^{\circ} \mathrm{C}$. Note that these calculations are based on the average fruit temperature. Despite the relative simplicity of this method, it provides a valuable first estimate as the heat stored in the product comprises the majority of the load (for FAC, (Thompson et al., 2008)).

In a more detailed approach, the average cooling load $\left(P_{A V G, 7 / 8, d}[\mathrm{~W}]\right)$ was calculated by including not only the product heat load but also heat transmission losses through the container walls, respiration heat, latent heat due to moisture evaporation, heat loss due to infiltration and ventilation and heat produced by equipment (evaporator fans). Details on this method can be found in (ASHRAE, 2010; Thompson, Mejia, \& Singh, 2010), which was adapted to the present study for container cooling. Note that a safety factor on the total load for possible discrepancies between design criteria and actual operation (usually $10 \%$ ) was not included here (ASHRAE, 2010). This detailed method provided a more realistic (time-averaged) cooling load and allowed a breakdown into the relative contributions of the loads. This calculation used a heat leakage value for the container (UA value) of $42 \mathrm{~W} \mathrm{~K}^{-1}$, an outside air temperature of $37.8^{\circ} \mathrm{C}$ and a respiration heat of $34.9 \mathrm{~W} \mathrm{t}^{-1}$.

Both averaged cooling loads provide sound estimates of the required cooling power that a reefer container should have to achieve a specific SECT. However, as the cooling behaviour of the produce 
Defraeye T., Verboven P., Opara U.L., Nicolai B., Cronjé P. (2015), Feasibility of ambient loading of citrus fruit into refrigerated containers for cooling during marine transport, Biosystems Engineering 134, 20-30. http://dx.doi.org/10.1016/j.biosystemseng.2015.03.012

is exponential in nature (Thompson et al., 2008), the required cooling power will be higher at the start than later in the process. As such, these average loads will to some extent under predict the required capacity, particularly for short cooling times, as in FAC. Thus determining the peak cooling load $\left(P_{\text {peak }}\right)$ might be more appropriate. The latter was calculated based on the momentary cooling rate at the start of cooling $R_{0}\left[{ }^{\circ} \mathrm{Ch}^{-1}\right]$ (Fraser \& Eng, 1998; Thompson et al., 2008):

$$
\begin{aligned}
& R_{0}=\frac{\ln (8)}{t_{7 / 8}}\left(T_{i n i}-T_{\text {air }}\right) \\
& P_{\text {peak }}=m c_{p} R_{0}=m c_{p} \frac{\ln (8)}{t_{7 / 8}}\left(T_{i n i}-T_{\text {air }}\right)
\end{aligned}
$$

This peak power can also be written as:

$$
P_{\text {peak }}=P_{A V G, 7 / 8, s} \frac{\left(T_{\text {ini }}-T_{\text {air }}\right)}{\left(T_{\text {ini }}-T_{7 / 8}\right)} \ln (8)=P_{A V G, 7 / 8, s} \frac{8}{7} \ln (8)=2.38 P_{A V G, 7 / 8, s}
$$

As this peak cooling power is solely based on the (theoretical) cooling curve of the produce, it is independent of other additional heat sources or losses. In practice however, even FAC facilities are often not designed for this peak cooling load (Fraser \& Eng, 1998), due to the high associated cost. Hence a compromise is often made by installing only a fraction (e.g. 2/3, (Fraser \& Eng, 1998)) of this peak power and accepting slightly slower cooling. These peak heat loads are also usually not considered in cooling calculations for FAC facilities (ASHRAE, 2010; Thompson et al., 2010). Although the aforementioned calculations allow the required cooling power of a reefer container to be estimated for a specific SECT, this does not imply that this SECT will be attained for the given configuration (box design, stacking, etc.) under the specific operating conditions (airspeed, etc.), as the SECT is a system characteristic with a complex multivariate dependency (see above). This means that it is well possible that the fruits cannot be cooled down sufficiently fast within the SECT associated with a specific calculated cooling capacity, for example due to the presence of packaging. 
Defraeye T., Verboven P., Opara U.L., Nicolai B., Cronjé P. (2015), Feasibility of ambient loading of citrus fruit into refrigerated containers for cooling during marine transport, Biosystems Engineering 134, 20-30. http://dx.doi.org/10.1016/j.biosystemseng.2015.03.012

This implies that the heat removal from the fruit is not optimal, by which the temperature rise of the return air temperature, compared to the supply air temperature, is rather limited. In addition, the fruits do not necessarily cool at the same speed. To verify the performance of ambient loading in practice, a corresponding experiment was also performed.

\subsection{Full-scale experiment on reefer container}

After harvest, the 'Navel' oranges received standard commercial treatments (thiabendazole, $500 \mathrm{mg}$, l-1; imazalil, $500 \mathrm{mg}, \mathrm{l}-1$; 2,4-dichlorophenoxyacetic acid, $125 \mathrm{mg}, \mathrm{l}-1$ ) and a polyethylene citrus wax was applied. After treatment, the oranges were packed, placed on pallets and loaded into the reefer container, which all took place within $3 \mathrm{~d}$ after harvest. The gap at the end of the container, where the T-bar floor was not covered by a pallet, was closed to avoid an airflow short circuit at this location (shown in orange in Fig. 2). After the container was sealed (September $3^{\text {rd }} 2013$ ), the following cooling procedure was adopted: $48 \mathrm{~h}$ at $3.5^{\circ} \mathrm{C}, 72 \mathrm{~h}$ at $0^{\circ} \mathrm{C}, 408 \mathrm{~h}(17 \mathrm{~d})$ at $-1.5^{\circ} \mathrm{C}$. The temperatures were the thermostat set temperatures at the inlet of the container. The entire experiment lasted $22 \mathrm{~d}$ during which refrigeration unit fans operated continuously. This duration was typical for the time required for the cold disinfestation protocol used to protect against false codling moth. This step-down cooling was standard practice, where reducing the set temperature immediately to $-1.5^{\circ} \mathrm{C}$ was found to induce more chilling injury, probably due to the drastic exposure of "warm" fruit to sub-zero cold air. It should be noted that the set temperature was lower than that envisaged for the final fruit temperature (between -0.5 and $2{ }^{\circ} \mathrm{C}$ for cold disinfestation, depending on the export market) to offset the heat produced by fruit respiration as well as additional heat sources (e.g. heat transmission losses). No repetitions of the experiment were performed for this feasibility test because of the large cost that was associated with filling an entire container with fruit for three weeks and the subsequent large losses in the commercial value of the fruit. 
Defraeye T., Verboven P., Opara U.L., Nicolai B., Cronjé P. (2015), Feasibility of ambient loading of citrus fruit into refrigerated containers for cooling during marine transport, Biosystems Engineering 134, 20-30. http://dx.doi.org/10.1016/j.biosystemseng.2015.03.012

Prior to loading, temperature sensors were inserted centrally in the pulp of several oranges, via an incision (i-buttons ${ }^{\circledast}$, Maxim, CA, USA, accuracy of $\pm 0.5^{\circ} \mathrm{C}$, data logging every $20 \mathrm{~min}$ ). Three boxes per pallet contained monitoring oranges (Fig. 2), namely at layers 1 (under), 5 (middle) and 8 (upper). Seven pallets were monitored this way (nrs. 1, 4, 8, 11, 13, 16 and 19). Thus, the spatial variation of the cooling rate with respect to the location of the pallet in the container and the height of the box on the pallet could be determined. Fruit core temperatures are usually monitored by official sensors in the containers, for example to evaluate the efficacy of disinfestation treatments during overseas transport. The amount of sensors used commercially is however much less than in the current experiment: typically three sensors are installed in a reefer container during transport. From the profiles of the core temperatures, the SECT and half cooling time (HCT) were determined. Note that this SECT differs to some extent with the one used in the calculations (section 2.2) due to: (1) the step-down cooling, by which SECT and HCT do not correspond entirely to an exponential cooling curve; (2) the fact that the core temperature (experiments) was used instead of the average fruit temperature (calculations).

At the end of the experiment, chilling injury was evaluated for the middle and upper box on each pallet in which a temperature sensor was located to determine if fruit quality was negatively affected. Thus, each orange in these boxes was scored according to a chilling-injury severity index $(\mathrm{Cl}, 0-3)$. Fruit scored as 1 had a chilling injury lesion covering $0-5 \%$ of the fruit rind surface, fruit scored as 2 had a 5 - $15 \%$ chilling injury lesion, whereas chilling injury lesions larger than $15 \%$, which are scored as 3, were not evident in the experiment. The average chilling injury index $\left(\mathrm{Cl}_{a v g}, 0\right.$ 3) for the entire box was calculated as $C_{\text {avg }}=\left(\sum C l \times\right.$ no. of fruit in each class $) /$ no. of fruit per box. Although the lowest boxes probably experienced the highest chilling injury, time restrictions did not allow these boxes to be evaluated. 
Defraeye T., Verboven P., Opara U.L., Nicolai B., Cronjé P. (2015), Feasibility of ambient loading of citrus fruit into refrigerated containers for cooling during marine transport, Biosystems Engineering 134, 20-30. http://dx.doi.org/10.1016/j.biosystemseng.2015.03.012

\section{$\underline{\text { 3. Results }}$}

\subsection{Required vs. available cooling capacity}

In Fig. 3a, the required cooling power, calculated by different methods (section 2.2), is shown as a function of the cooling time, for which the SECT is used. The intersection with the available net cooling (refrigeration) power of the Maersk Starcool refrigeration unit $\left(\approx 10.7 \mathrm{~kW}\right.$ at $-1.5^{\circ} \mathrm{C}$ working temperature) is also indicated, which is $2.1,3.9$ and $4.9 \mathrm{~d}$ for the simplified-average, detailedaverage and peak power calculations, respectively. These SECT values correspond to the 2 to $6 \mathrm{~d}$ which Heap (Heap, 2006) reports for the SECT of cooling of produce during transport. In the most negative situation, i.e., when the largest value of the calculated cooling power was considered, i.e. the peak value, the SECT was still below 6 days. However, all calculated SECT were considerably longer than those reported for FAC ( 1 h - 24 h, (Defraeye et al., 2013, 2014; Thompson \& Chen, 1988; Thompson et al., 2008)). Note however that the calculated intersection points assume that such a SECT can be achieved by the system under given operating conditions. The SECT can be longer in practice, for example due to insufficient vent holes, leading to suboptimal heat removal. Also, it should be noted that the available net cooling power of the container varies depending on the set temperature of the container and the efficiency (e.g. coefficient of performance) with which the cooling unit works.

When comparing the three methods, clear differences can be found. The peak power poses the strictest requirement in the present study. This implies that if the calculated peak power is higher than the available power of the reefer container at a specific SECT, thus for all SECT left from the intersection point between both curves, this SECT cannot be reached in practice as the required power is not available. A particularly interesting finding is that the required average power (detailed calculation, blue curve) can become the dominant power curve, since at some point the peak power curve drops below it. Therefore, it can become the most unfavourable cooling load (intersection 
Defraeye T., Verboven P., Opara U.L., Nicolai B., Cronjé P. (2015), Feasibility of ambient loading of citrus fruit into refrigerated containers for cooling during marine transport, Biosystems Engineering 134, 20-30. http://dx.doi.org/10.1016/j.biosystemseng.2015.03.012

point), for example for less powerful cooling units (lower available power) or higher heat loads/losses (higher average power required). So for longer cooling times, the additional heat loads and not the peak power will determine the required power, and the corresponding achievable SECT. The peak power calculation, which is developed to design FAC facilities and which does not account for heat losses as it is only based on the cooling curve characteristics ( $t_{7 / 8}$, Eq. (3)), is thus less suitable for processes with long cooling times, as for example found for ambient cooling.

In Fig. 3b, the percentage of the total average cooling load which is covered by the product heat load (i.e. related to the field heat to be removed, see section 2.2 and Eq.(1)) is given as a function of the SECT, as calculated by the detailed method $\left(P_{A V G, 7 / 8, d}\right)$. The longer the SECT, the less important the product heat load becomes. This is not surprising as the required power $\left(\mathrm{J} \mathrm{s}^{-1} \mathrm{or} \mathrm{W}\right)$ to remove the field heat from the fruit decreases with increasing SECT, whereas other heat loads are almost constant over time, i.e. independent of the considered timeframe (SECT). For FAC facilities, Thompson et al. (Thompson et al., 2008) state that these other heat loads equal about $25 \%$ of the product heat load, which agrees with Fig. $3 b$ for relatively short cooling times $(<1 \mathrm{~d})$, characteristic for FAC. The fact that the simplified method $\left(P_{A V G, 7 / 8, S}\right)$ only accounts for the field heat, leading to a decreasing power requirement with increasing SECT, and not for other (almost constant) contributions, is the reason for the differences with the detailed-average method $\left(P_{A V G, 7 / 8, d}\right)$.

With respect to the applicability of ambient loading for cold disinfestation treatments, regulations for export from South Africa require that the fruit must be continuously precooled for a period of at least $72 \mathrm{~h}$, of which the pulp temperatures must be below a certain threshold (between -0.5 and 2 ${ }^{\circ} \mathrm{C}$, depending on the export market) during the last $24 \mathrm{~h}$. After fruits are stable at this threshold for $24 \mathrm{~h}$, the official cold treatment starts (e.g. mandatory $22 \mathrm{~d}$ for false codling moth). For ambient loading, this implies that if it is possible to attain the threshold temperature for example in a 5-day window (plus another 24 hours stable at this temperature), the fruit could be deemed ready for the official cold disinfestation. Achieving a SECT in less than 5 days in a reefer container was found to be 
Defraeye T., Verboven P., Opara U.L., Nicolai B., Cronjé P. (2015), Feasibility of ambient loading of citrus fruit into refrigerated containers for cooling during marine transport, Biosystems Engineering 134, 20-30. http://dx.doi.org/10.1016/j.biosystemseng.2015.03.012

theoretically possible from the present study (with $T_{7 / 8}=1.2^{\circ} \mathrm{C}$ ). Of course, this practice should imply that the fruit quality and shelf-life are not too much affected due to this longer precooling time in the reefer container, compared to FAC. It should be noted that for lower $T_{7 / 8}$, as required by some export markets (e.g. $-0.6^{\circ} \mathrm{C}$ for the USA), cooling times will be longer for a set air temperature of -1.5 ${ }^{\circ} \mathrm{C}$. Alternatively, a lower set air temperature than $-1.5^{\circ} \mathrm{C}$ can be used to still attain the aforementioned SECT. Such a lower temperature could however increase chilling injury and this should be verified first.

\subsection{Reefer container experiment}

This experiment aimed to identify the extent to which the predicted SECT can be achieved in practice, i.e. if the fruits can be cooled down as rapidly as theoretically possible by the reefer container. The temperature profiles measured in the centre of the fruit (pulp) are shown in Fig. 4 for the various sampling positions in the containers. However, two sensors were broken, namely in pallet 4 (upper box) and pallet 16 (bottom box). Corresponding SECT and HCT were determined from these profiles and they are reported in Fig. 5. Note that some older sensors did round the logged temperatures to $0.5^{\circ} \mathrm{C}$, which is equal to their accuracy.

From Fig. 4 and 5, it can be seen that large heterogeneity occurred in the rate with which the fruit in different boxes cool down. This heterogeneity occurred both with respect to the location of the pallet in the container and with respect to the position of the carton box (layer) on the pallet. It was evident that for nearly all pallets, the bottom box cooled more rapidly than the middle one, which in its turn cooled more rapidly than the upper box. However, the differences between middle and upper boxes were much smaller, indicating that the lower boxes cooled more rapidly and the air was heated up significantly when moving upwards through the subsequent boxes. The upper boxes cooled down about half as quickly as the lower ones, when comparing the SECT. Regarding differences in cooling rates between pallets, there did not seem to be a logical pattern. Pallets close to the cooling unit (nrs. 1, 4 and 13) did not necessarily cool down more rapidly than others. Such a 
Defraeye T., Verboven P., Opara U.L., Nicolai B., Cronjé P. (2015), Feasibility of ambient loading of citrus fruit into refrigerated containers for cooling during marine transport, Biosystems Engineering 134, 20-30. http://dx.doi.org/10.1016/j.biosystemseng.2015.03.012

random cooling pattern between different pallets was also noticed by Jedermann et al. (2014). At a specific height (one layer), the slowest cooling box over all pallets had a SECT up to four times longer than the fastest cooling pallet. It should be noted that the slight temperature increase found in the second hour of the experiment was probably due to a defrosting cycle during which time the fans were stopped. Finally, it should also be noted that some fruit temperatures reached a steady state at higher temperatures than others, indicating that cold disinfestation might be less effective at these locations.

Finally, the chilling injury index, as averaged for each box $\left(\mathrm{Cl}_{\text {avg }}\right)$, is reported in Fig. 5 . Note that it is rescaled from 0 to 3 (in section 2.3) to a scale from 0 to 100 , so it can be interpreted as the percentage of chilling injury per box. Note that this percentage reflects the degree of chilling injury and not the amount of fruit with chilling injury (see section 2.3). The middle layer clearly showed a higher chilling injury than the upper. Again, large heterogeneity was found between different pallets, with no clear logical pattern. There also appeared to be no clear relationship between the SECT and chilling injury (correlation coefficient $r^{2}<0.1$ ). Pallets 1 and 4 had short cooling times, but very limited chilling injury, whereas one would expect the most chilling injury to occur here. Pallets 11 and 19 also had limited chilling injury, but exhibited much longer cooling times, whereas, in contrast, pallets 8 and 13 also had long cooling times but showed large amounts of chilling injury.

\section{Discussion}

With respect to the magnitude of the SECT, higher values were found than the working (intersection) points calculated in section 3.1, especially for the upper boxes. So although the reefer container theoretically had sufficient cooling power to cool the fruits in less than 5 d to the SECT (section 3.1), this appeared not to be possible in practice. Several reasons are responsible for this mismatch:

- Differences between experiments and calculations as a step-down cooling was applied in the experiments, whereas calculations were based on immediate cooling to the set 
Defraeye T., Verboven P., Opara U.L., Nicolai B., Cronjé P. (2015), Feasibility of ambient loading of citrus fruit into refrigerated containers for cooling during marine transport, Biosystems Engineering 134, 20-30. http://dx.doi.org/10.1016/j.biosystemseng.2015.03.012

temperature. Step-down cooling was applied as a measure to avoid an excess of chilling injury, resulting from the low supply air temperatures which were required for the cold disinfestation protocol.

- $\quad$ The temperature profiles (Fig. 4) monitored the fruit core temperature, which did not exactly represent the average fruit temperature due to the finite thermal conductivity of the fruit. The average fruit temperature will already have reached the SECT before the core temperature reaches the SECT, resulting in longer measured SECT.

- Although the required (net) cooling power was available in the reefer container (section 3.1), so the container can 'do the job' in an acceptable timeframe, the cooling of the produce itself was too slow to attain the envisaged SECT for the present configuration. This could be caused by poor ventilation due to closing of vent holes (e.g., impropriate stacking or box design) or refrigerated air bypassing boxes via the gaps between the pallets. Thus the airflow short circuited between pallets, causing low heat removal and making the return air temperature (and thus its enthalpy) to remain relatively close to the supply air temperature. Thereby, the energy that was removed from the return air by the refrigeration unit, to bring it back to the set air temperature, was also limited, by which the refrigeration unit did not run at full capacity. Current research is underway to improve ventilation for vertical airflow, amongst others by sealing gaps between pallets and improving box design. However, it is also possible that in the first stages of cooling, the refrigeration unit cannot reduce the return air to the set air temperature, since the return air reaches high temperatures because the fruit is still warm.

Despite this mismatch, the very long SECT found in the present experiments for some boxes appears to suggest that the limiting factor for the fruit cooling rate is the amount of heat that can be removed from the fruit by airflow through the boxes, and not the installed cooling capacity of the reefer container, even though the latter is much lower than that normally used for FAC facilities. 
Defraeye T., Verboven P., Opara U.L., Nicolai B., Cronjé P. (2015), Feasibility of ambient loading of citrus fruit into refrigerated containers for cooling during marine transport, Biosystems Engineering 134, 20-30. http://dx.doi.org/10.1016/j.biosystemseng.2015.03.012

Jedermann et al. (2014) reported similar findings for the cooling of banana fruit packed in polyethylene bags within cardboard boxes. However, the plastic packaging they used (to reduce moisture losses) slowed down cooling more than compared with the present study. They found that only an estimated $10 \%$ of the reefer cooling capacity was effectively utilised for cooling of the fruit. These studies show that the available cooling capacity in a reefer container is often not fully utilised due to packaging and stacking issues. This indicates that a large potential exist for improving packaging design, which could affect the performance of ambient loading.

To assess such improvements towards enhanced cooling behaviour in more detail, advanced numerical methods can complement the basic calculations and experiments performed in the present study. Computational fluid dynamics (CFD) has been considered to be the most appropriate tool for this purpose (Defraeye et al., 2013, 2014; Dehghannya, Ngadi, \& Vigneault, 2011, 2012; Delele et al., 2013a, 2013b; Ferrua \& Singh, 2009; Smale, Moureh, \& Cortella, 2006; Verboven, Flick, Nicolaï, \& Alvarez, 2006; Zou, Opara, \& McKibbin, 2006b, 2006a). This tool may be particularly useful to determine the actual SECT for the individual boxes on a pallet, the heterogeneity of the cooling rate of the individual oranges within a single box and the influence of gaps between pallets (airflow short circuiting). To date, this tool has been mainly used for precooling and storage applications, but rarely for refrigerated containers. CFD is currently being explored by the authors as a tool for investigating ambient loading.

\section{Conclusions and future outlook}

The present study explored the feasibility of an alternative cold-chain protocol based on the ambient or warm loading of citrus fruit into reefer containers for cooling during marine transport. This practice offers a considerable logistical advantage as it avoids the use of extra infrastructure and the costs and time associated with forced-air precooling. This makes it particularly interesting within the context of cold disinfestation treatment, which is increasingly demanded, for example, by the South 
Defraeye T., Verboven P., Opara U.L., Nicolai B., Cronjé P. (2015), Feasibility of ambient loading of citrus fruit into refrigerated containers for cooling during marine transport, Biosystems Engineering 134, 20-30. http://dx.doi.org/10.1016/j.biosystemseng.2015.03.012

African citrus export markets. If this practice is applied immediately after palletisation at the pack house instead of at the harbour prior to shipping, ambient loading could also invoke an earlier start of the cold chain, which could also extend shelf-life. However, it is currently only successful for export of sweet oranges to non-disinfestation markets (at $4-7^{\circ} \mathrm{C}$ ) and a systematic exploration of the cooling process is still largely unexplored.

Although calculations in the present study showed that a typical reefer container has theoretically sufficient cooling power to cool fruit in less than $5 \mathrm{~d}$ to the seven-eight cooling time (SECT), experiments showed that in practice there are longer SECT, particularly for boxes in the upper part of the pallets. However, it should be noted that step-down cooling was applied to avoid an excess of fruit chilling injury associated with the cold disinfestation protocol temperatures. Hence the fruits could not be cooled down quickly enough. Thus, the reefer cooling unit was not used to its full capacity. Although the installed airflow and cooling capacity are fixed design variables for a reefer container, other improvements to enhance the heat removal rate from the fruit can still be made to the current practice:

- Box design and their stacking patterns on the pallet can be optimised for vertical cooling, and blockage of vent holes by the wooden pallet base can be reduced.

- Airflow short-circuits between the pallets can be reduced. This should however be done during loading of the container which poses some practical challenges.

Such improvements should lead to a higher fruit cooling rate and a shorter SECT, and also to a better uniformity in the cooling rates between the different pallets and between different layers of boxes on a pallet, for which CFD can nicely complement current experimental research. The resulting higher heat removal rate could also lead to a more efficient use of the cooling capacity installed in the reefer container. In addition, step-down cooling could be replaced by direct cooling to the final set temperature for higher set temperatures (i.e. not sub-zero), reducing the risk of chilling injury. 
Defraeye T., Verboven P., Opara U.L., Nicolai B., Cronjé P. (2015), Feasibility of ambient loading of citrus fruit into refrigerated containers for cooling during marine transport, Biosystems Engineering 134, 20-30. http://dx.doi.org/10.1016/j.biosystemseng.2015.03.012

More systematic studies on container cooling within the context of ambient loading should lead to an optimisation of the technique with respect to fruit quality, shelf-life and associated food losses but they could also lead to its use for more sensitive citrus varieties or other perishable fruit species, thereby removing the need for precooling with these products. Furthermore, instead of envisioning ambient loading as a less efficient way of forced-air cooling (FAC), one could also see it as placing pallets in an improved cool store with better airflow conditions, presumably leading to more rapid cooling than normal cool stores. Cool stores inland or at harbours are currently still a popular way of precooling several fruits prior to long-haul transport. Ambient loading could be considered as offering a solution somewhere in between a precooling facility and a cold store. The latter should however be assessed together with its economic feasibility, as the reefer container is utilised longer when loaded directly at the pack house.

Currently, the main challenge of ambient loading is to improve the cooling rate of the fruit and the uniformity between pallets and individual boxes. This will, however, not necessarily lead to the optimum fruit quality (e.g. by excessive chilling injury), even though such cooling is much slower than in FAC. Chilling injury is particularly an issue when cooling with sub-zero air temperatures for cold disinfestation treatments. Optimising ambient loading will thus require a compromise between cooling rate and fruit quality, e.g., by applying step-down cooling, and this is a major focus for the South African citrus industry. In addition, the present study did not focus on energy consumption for ambient loading or the comparison with FAC. This is a critical point for future research due to the large amount of energy consumed in the cold chain for fresh produce. Large energy savings are expected to lie in optimising fan operation and fan control in reefer containers (GDV, 2014), since they consume a large amount of energy and fans also produce heat. Furthermore, optimisation of packaging design with respect to aerodynamic resistance can produce energy savings since it affects the required fan power. 
Defraeye T., Verboven P., Opara U.L., Nicolai B., Cronjé P. (2015), Feasibility of ambient loading of citrus fruit into refrigerated containers for cooling during marine transport, Biosystems Engineering 134, 20-30. http://dx.doi.org/10.1016/j.biosystemseng.2015.03.012

\section{Acknowledgements}

Thijs Defraeye is a postdoctoral fellow of the Research Foundation - Flanders (FWO) and acknowledges its support. We would also like to thank Gerard Grinwis, Henrik Lindhardt and JohannKarel Bosman of Maersk Container Industry AS and Richard Lawton from Cambridge Refrigeration Technology for providing us with the necessary information for the cooling calculations. In addition we would like to thank John Perold, Andre Mouton, Marcellis Adams and Adriaan Botha of Sundays River Citrus Co-op and Keith Roxbury of Capespan for their help with fruit and logistical support. U.L. Opara's contribution was supported by the South African Research Chairs Initiative of the Department of Science and Technology and the National Research Foundation. We also acknowledge the support of the World Food System Center (WFSC) of ETH Zürich (www.worldfoodsystem.ethz.ch). 
Defraeye T., Verboven P., Opara U.L., Nicolai B., Cronjé P. (2015), Feasibility of ambient loading of citrus fruit into refrigerated containers for cooling during marine transport, Biosystems Engineering 134, 20-30. http://dx.doi.org/10.1016/j.biosystemseng.2015.03.012

\section{Tables}

Table 1. Characteristics of forced-air precooling and ambient loading

$\begin{array}{lll}\text { Characteristic } & \text { Forced-air precooling Ambient loading }\end{array}$

(FAC)

Airflow direction $\quad$ Horizontal $\quad$ Vertical

\begin{tabular}{lll}
\hline Airflow rate & High & Low \\
\hline Installed cooling capacity & High & Low (fixed) \\
\hline Pathway air & Short & Long \\
& & \\
\hline Airflow short-circuits & Closed & Difficult to close \\
& & (accessibility) \\
\hline Continuous airflow & Yes & Very rare (also \\
pathway via vent holes & & blocking of vent \\
by special box design and & & holes by pallet \\
stacking & & base)
\end{tabular}


Defraeye T., Verboven P., Opara U.L., Nicolai B., Cronjé P. (2015), Feasibility of ambient loading of citrus fruit into refrigerated containers for cooling during marine transport, Biosystems Engineering 134, 20-30. http://dx.doi.org/10.1016/j.biosystemseng.2015.03.012

\section{Figure captions}

Fig. 1. Illustration of airflow for forced-air precooling (horizontal) and ambient loading in a refrigerated container (vertical) for an 8-layer, high-cube citrus pallet (10 Supervent cartons per layer, each packed with $\pm 16 \mathrm{~kg}$ of fruit).

Fig. 2. Side and top cross-sectional views of a reefer container with stacking pattern of the pallets and indication of the box layers. The pallets in which temperature sensors were provided are numbered. The inner dimensions of the container are given.

Fig. 3. (a) Average required cooling power, calculated based on simplified and detailed methods, and peak cooling power as a function of cooling time (i.e. SECT). The available (net) cooling power in the reefer container is also presented. (b) Percentage of product heat load, relative to the total average cooling load, as a function of the SECT, calculated based on the detailed method.

Fig. 4. Temperatures in the centre of the orange pulp for different boxes (upper: up, middle: mid, under: und) for seven of the pallets in the container (pallets 1, 4, 8, 11, 13, 16, 19 in Fig. 2). The set temperature for the step down cooling is indicated by the bold grey line.

Fig. 5. Seven-eighths cooling time, half cooling time and chilling injury index for different pallets within the container, as a function of height of the box on the pallet (upper, middle or under). Minimum and maximum values are underlined. 
Defraeye T., Verboven P., Opara U.L., Nicolai B., Cronjé P. (2015), Feasibility of ambient loading of citrus fruit into refrigerated containers for cooling during marine transport, Biosystems Engineering 134, 20-30. http://dx.doi.org/10.1016/j.biosystemseng.2015.03.012

\section{$\underline{\text { References }}$}

Ambaw, A., Verboven, P., Delele, M. A., Defraeye, T., Tijskens, E., Schenk, A., \& Nicolai, B. M. (2013). CFD Modelling of the 3D Spatial and Temporal Distribution of 1-methylcyclopropene in a Fruit Storage Container. Food and Bioprocess Technology, 6(9), 2235-2250.

Arduino, G., Carrillo Murillo, D., \& Parola, F. (2013). Refrigerated container versus bulk: evidence from the banana cold chain. Maritime Policy \& Management, 1-18.

ASHRAE. (2010). ASHRAE Handbook - Refrigeration: systems and applications (SI edition). Atlanta.

Brosnan, T., \& Sun, D. (2001). Precooling techniques and applications for horticultural products - a review. International Journal of Refrigeration, 24, 154-170.

CGA. (2013). Citrus Growers Association of Southern Africa: Key industry statistics for citrus growers 2013.

Defraeye, T., Lambrecht, R., Ambaw, A., Delele, M. A., Opara, U. L., Cronjé, P., ... Nicolai, B. (2013). Forced-convective cooling of citrus fruit: Package design. Journal of Food Engineering, 118, 818.

Defraeye, T., Lambrecht, R., Delele, M. A., Ambaw, A., Opara, U. L., Cronjé, P., ... Nicolai, B. (2014). Forced-convective cooling of citrus fruit: Cooling conditions and energy consumption in relation to package design. Journal of Food Engineering, 121, 118-127.

Dehghannya, J., Ngadi, M., \& Vigneault, C. (2010). Mathematical modeling procedures for airflow, heat and mass transfer during forced convection cooling of produce: A review. Food Engineering Reviews, 2(4), 227-243.

Dehghannya, J., Ngadi, M., \& Vigneault, C. (2011). Mathematical modeling of airflow and heat transfer during forced convection cooling of produce considering various package vent areas. Food Control, 22(8), 1393-1399.

Dehghannya, J., Ngadi, M., \& Vigneault, C. (2012). Transport phenomena modelling during produce cooling for optimal package design: Thermal sensitivity analysis. Biosystems Engineering, 111(3), 315-324.

Delele, M. A., Ngcobo, M. E. K., Getahun, S. T., Chen, L., Mellmann, J., \& Opara, U. L. (2013a). Studying airflow and heat transfer characteristics of a horticultural produce packaging system using a 3-D CFD model. Part I: Model development and validation. Postharvest Biology and Technology, 86, 536-545.

Delele, M. A., Ngcobo, M. E. K., Getahun, S. T., Chen, L., Mellmann, J., \& Opara, U. L. (2013b). Studying airflow and heat transfer characteristics of a horticultural produce packaging system using a 3-D CFD model. Part II: Effect of package design. Postharvest Biology and Technology, $86,546-555$. 
Defraeye T., Verboven P., Opara U.L., Nicolai B., Cronjé P. (2015), Feasibility of ambient loading of citrus fruit into refrigerated containers for cooling during marine transport, Biosystems Engineering 134, 20-30. http://dx.doi.org/10.1016/j.biosystemseng.2015.03.012

Delele, M. A., Schenk, A., Tijskens, E., Ramon, H., Nicolaï, B. M., \& Verboven, P. (2009). Optimization of the humidification of cold stores by pressurized water atomizers based on a multiscale CFD model. Journal of Food Engineering, 91(2), 228-239.

Delele, M. A., Tijskens, E., Atalay, Y. T., Ho, Q. T., Ramon, H., Nicolaï, B. M., \& Verboven, P. (2008). Combined discrete element and CFD modelling of airflow through random stacking of horticultural products in vented boxes. Journal of Food Engineering, 89(1), 33-41.

FAO. (2013). FAO Statistical Yearbook 2013 (www.fao.org). (FAO, Ed.) (pp. 1-307). Rome.

Ferrua, M. J., \& Singh, R. P. (2009). Design guidelines for the forced-air cooling process of strawberries. International Journal of Refrigeration, 32(8), 1932-1943.

Fitzgerald, W. B., Howitt, O. J. a., Smith, I. J., \& Hume, A. (2011). Energy use of integral refrigerated containers in maritime transportation. Energy Policy, 39(4), 1885-1896.

Fraser, H. W., \& Eng, P. (1998). Factsheet: Tunnel forced-air coolers for fresh fruits \& vegetables (pp. 1-12).

GDV. (2014). Gesamtverband der Deutschen Versicherungswirtschaft : Container Handbook.

Heap, R. D. (2006). Cold chain performance issues now and in the future. In Innovative equipment and systems for comfort \& food preservation (pp. 1-13). Auckland.

Hoang, M. H., Laguerre, O., Moureh, J., \& Flick, D. (2012). Heat transfer modelling in a ventilated cavity loaded with food product: Application to a refrigerated vehicle. Journal of Food Engineering, 113(3), 389-398.

James, S. J., James, C., \& Evans, J. a. (2006). Modelling of food transportation systems - a review. International Journal of Refrigeration, 29(6), 947-957.

Jedermann, R., Geyer, M., Praeger, U., \& Lang, W. (2013). Sea transport of bananas in containers Parameter identification for a temperature model. Journal of Food Engineering, 115, 330-338.

Jedermann, R., Praeger, U., Geyer, M., \& Lang, W. (2014). Remote quality monitoring in the banana chain. Philosophical Transactions of the Royal Society A, 372, 20130303.

Jiménez-Ariza, T., Correa, E. C., Diezma, B., Silveira, A. C., Zócalo, P., Arranz, F. J., ... Ruiz-Altisent, M. (2014). The phase space as a new representation of the dynamical behaviour of temperature and enthalpy in a reefer monitored with a multidistributed sensors network. Food and Bioprocess Technology, 7(6), 1793-1806.

Maersk. (2014).

Moureh, J., \& Flick, D. (2004). Airflow pattern and temperature distribution in a typical refrigerated truck configuration loaded with pallets. International Journal of Refrigeration, 27(5), 464-474.

Moureh, J., Menia, N., \& Flick, D. (2002). Numerical and experimental study of airflow in a typical refrigerated truck configuration loaded with pallets. Computers and Electronics in Agriculture, 34(1-3), 25-42. 
Defraeye T., Verboven P., Opara U.L., Nicolai B., Cronjé P. (2015), Feasibility of ambient loading of citrus fruit into refrigerated containers for cooling during marine transport, Biosystems Engineering 134, 20-30. http://dx.doi.org/10.1016/j.biosystemseng.2015.03.012

Moureh, J., Tapsoba, S., Derens, E., \& Flick, D. (2009). Air velocity characteristics within vented pallets loaded in a refrigerated vehicle with and without air ducts. International Journal of Refrigeration, 32(2), 220-234.

Nahor, H. B., Hoang, M. L., Verboven, P., Baelmans, M., \& Nicolaï, B. M. (2005). CFD model of the airflow, heat and mass transfer in cool stores. International Journal of Refrigeration, 28(3), 368-380.

Pathare, P. B., Opara, U. L., Vigneault, C., Delele, M. A., \& Al-Said, F. A.-J. (2012). Design of packaging vents for cooling fresh horticultural produce. Food and Bioprocess Technology, 5, 2031-2045.

PPECB. (2013). Perishable Products Export Control Board - Export directory 2013: PPECB procedural manual on general procedure, loading and carrying temperature requirements for the export of perishable products. Section 4:23.

Rodríguez-Bermejo, J., Barreiro, P., Robla, J. I., \& Ruiz-García, L. (2007). Thermal study of a transport container. Journal of Food Engineering, 80(2), 517-527.

Smale, N. J., Moureh, J., \& Cortella, G. (2006). A review of numerical models of airflow in refrigerated food applications. International Journal of Refrigeration, 29(6), 911-930.

Tanner, D. J., \& Amos, N. D. (2003). Temperature variability during shipments of fresh produce. Acta Horticulturae, 599, 193-203.

Tapsoba, M., Moureh, J., \& Flick, D. (2006). Airflow patterns in an enclosure loaded with slotted pallets. International Journal of Refrigeration, 29(6), 899-910.

Tapsoba, M., Moureh, J., \& Flick, D. (2007). Airflow patterns in a slot-ventilated enclosure partially loaded with empty slotted boxes. International Journal of Heat and Fluid Flow, 28(5), 963-977.

Thompson, A. K. (2003). Fruit and Vegetables - Harvesting, Handling and Storage (First). Oxford: Blackwell Publishing Ltd.

Thompson, J. F. (2004). Pre-cooling and storage facilities. In USDA (Ed.), USDA Agriculture Handbook Number 66: The Commercial Storage of Fruits, Vegetables, and Florist and Nursery Stocks (pp. 1-10). USDA.

Thompson, J. F., \& Chen, Y. L. (1988). Comparative energy use of vacuum, hydro and forced air coolers for fruit and vegetables. ASHRAE Transactions, 94(1), 1427-1432.

Thompson, J. F., Mejia, D. C., \& Singh, R. P. (2010). Energy use in commercial forced-air coolers for fruit. Applied Engineering in Agriculture, 26(5), 919-924.

Thompson, J. F., Mitchell, F. G., Rumsey, R. T., Kasmire, R. F., \& Crisosto, C. H. (2008). Commercial cooling of fruit, vegetables and flowers (p. 61). California: University of California.

Verboven, P., Flick, D., Nicolaï, B. M., \& Alvarez, G. (2006). Modelling transport phenomena in refrigerated food bulks, packages and stacks: basics and advances. International Journal of Refrigeration, 29(6), 985-997. 
Defraeye T., Verboven P., Opara U.L., Nicolai B., Cronjé P. (2015), Feasibility of ambient loading of citrus fruit into refrigerated containers for cooling during marine transport, Biosystems Engineering 134, 20-30. http://dx.doi.org/10.1016/j.biosystemseng.2015.03.012

Zou, Q., Opara, U. L., \& McKibbin, R. (2006a). A CFD modeling system for airflow and heat transfer in ventilated packaging for fresh foods: I. Initial analysis and development of mathematical models. Journal of Food Engineering, 77(4), 1037-1047.

Zou, Q., Opara, U. L., \& McKibbin, R. (2006b). A CFD modeling system for airflow and heat transfer in ventilated packaging for fresh foods: II. Computational solution, software development, and model testing. Journal of Food Engineering, 77(4), 1048-1058. 
Defraeye T., Verboven P., Opara U.L., Nicolai B., Cronjé P. (2015), Feasibility of ambient loading of citrus fruit into refrigerated containers for cooling during marine transport, Biosystems Engineering 134, 20-30. http://dx.doi.org/10.1016/j.biosystemseng.2015.03.012

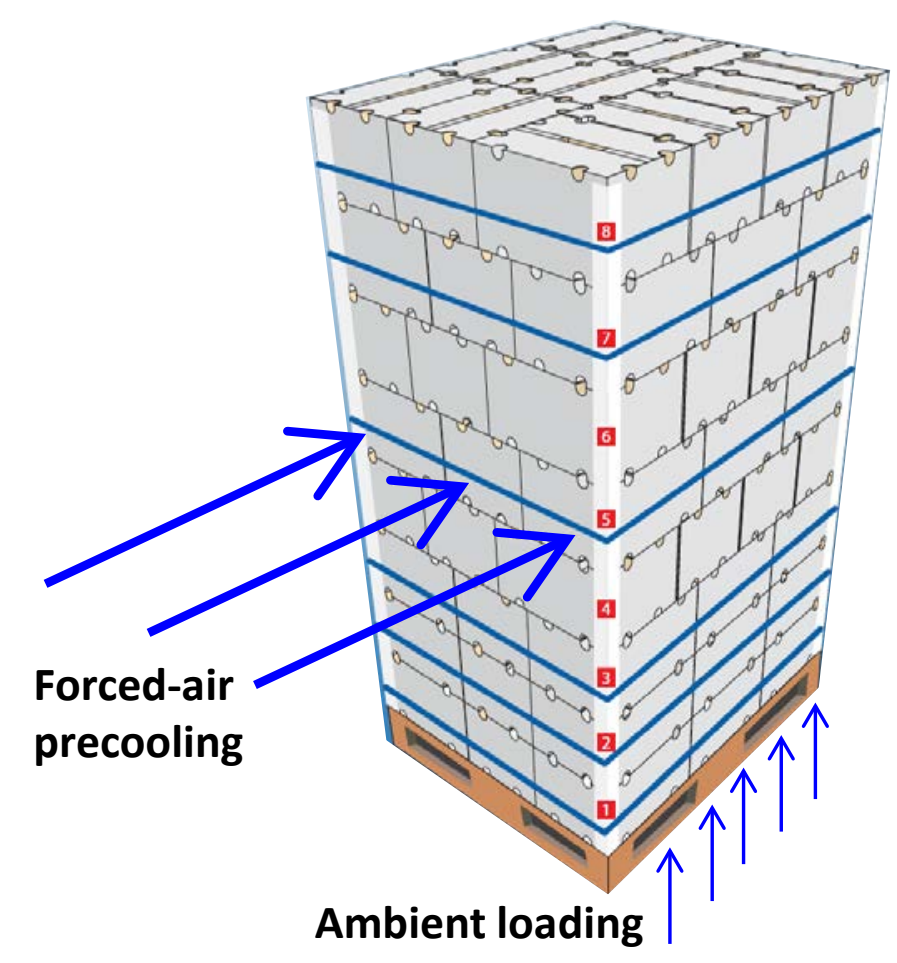

Fig. 1. Illustration of airflow for forced-air precooling (horizontal) and ambient loading in a refrigerated container (vertical) for an 8-layer, high-cube citrus pallet (10 Supervent cartons per layer, each packed with $\pm 16 \mathrm{~kg}$ of fruit). 
Defraeye T., Verboven P., Opara U.L., Nicolai B., Cronjé P. (2015), Feasibility of ambient loading of citrus fruit into refrigerated containers for cooling during marine transport, Biosystems Engineering 134, 20-30. http://dx.doi.org/10.1016/j.biosystemseng.2015.03.012

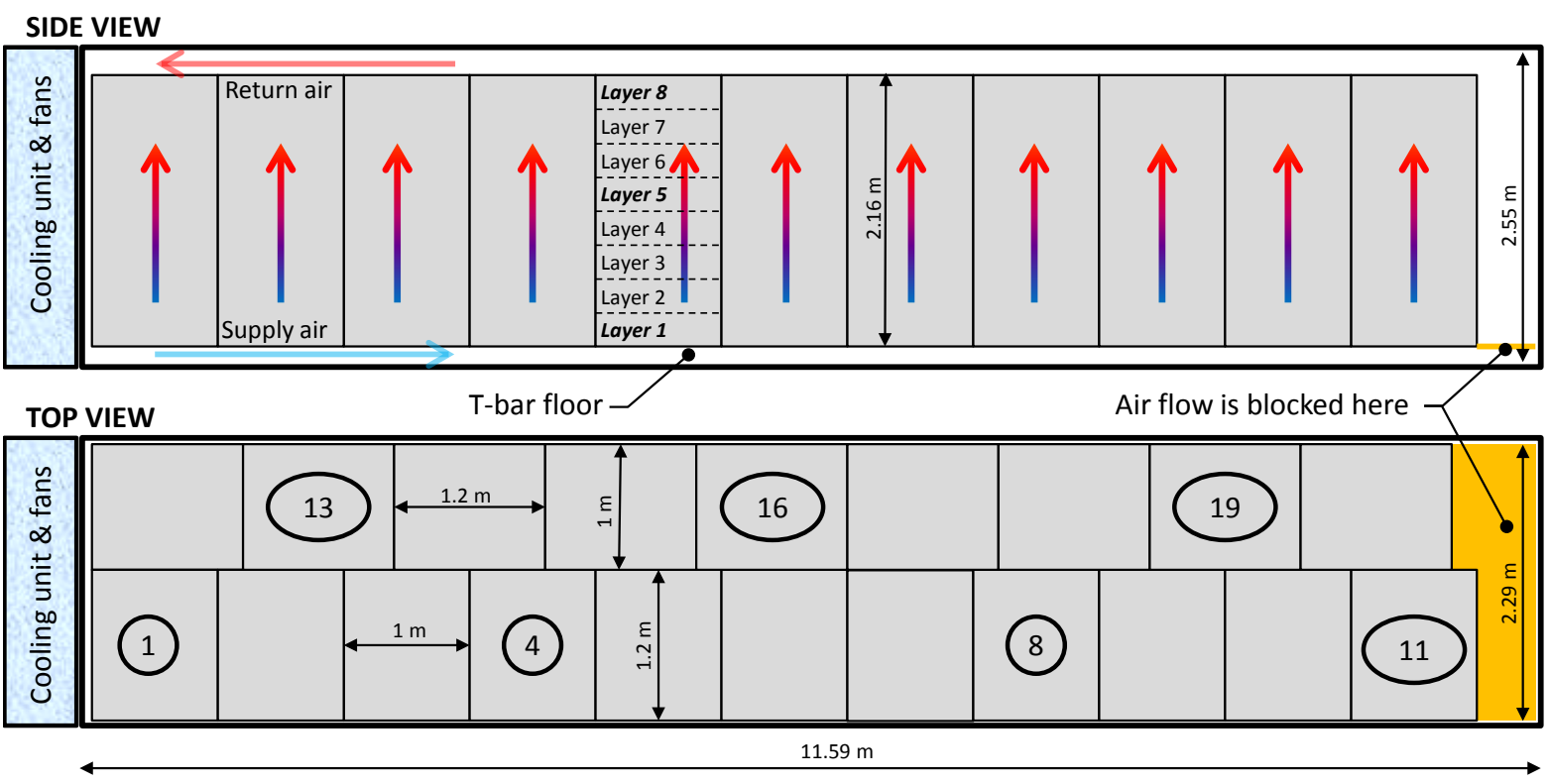

Fig. 2. Side and top cross-sectional views of a reefer container with stacking pattern of the pallets and indication of the box layers. The pallets in which temperature sensors were provided are numbered. The inner dimensions of the container are given. 
Defraeye T., Verboven P., Opara U.L., Nicolai B., Cronjé P. (2015), Feasibility of ambient loading of citrus fruit into refrigerated containers for cooling during marine transport, Biosystems Engineering

134, 20-30. http://dx.doi.org/10.1016/j.biosystemseng.2015.03.012
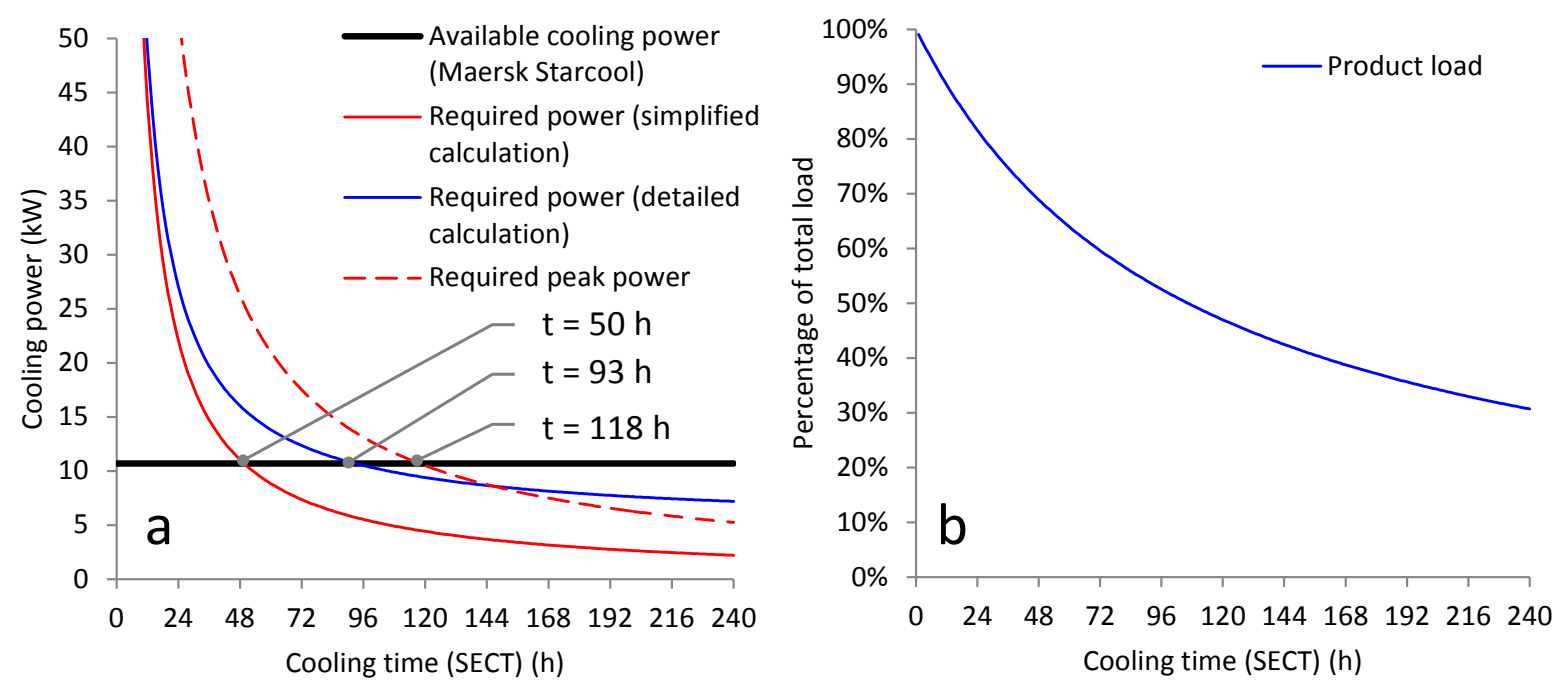

Fig. 3. (a) Average required cooling power, calculated based on simplified and detailed methods, and peak cooling power as a function of cooling time (i.e. SECT). The available (net) cooling power in the reefer container is also presented. (b) Percentage of product load, relative to the total average cooling load, as a function of the SECT, calculated based on the detailed method. 
Defraeye T., Verboven P., Opara U.L., Nicolai B., Cronjé P. (2015), Feasibility of ambient loading of citrus fruit into refrigerated containers for cooling during marine transport, Biosystems Engineering 134, 20-30. http://dx.doi.org/10.1016/j.biosystemseng.2015.03.012

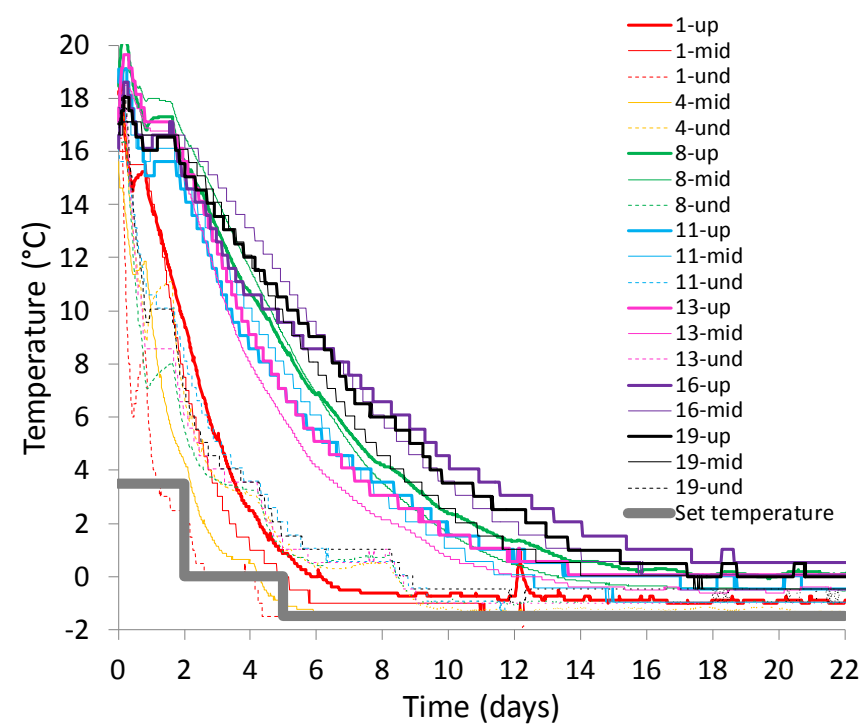

Fig. 4. Temperatures in the centre of the orange pulp for different boxes (upper: up, middle: mid, under: und) for seven of the pallets in the container (pallets 1, 4, 8, 11, 13, 16, 19 in Fig. 2). The set temperature for the step down cooling is indicated by the bold grey line. 
Defraeye T., Verboven P., Opara U.L., Nicolai B., Cronjé P. (2015), Feasibility of ambient loading of citrus fruit into refrigerated containers for cooling during marine transport, Biosystems Engineering 134, 20-30. http://dx.doi.org/10.1016/j.biosystemseng.2015.03.012

$7 / 8$ cooling time (SECT - days)

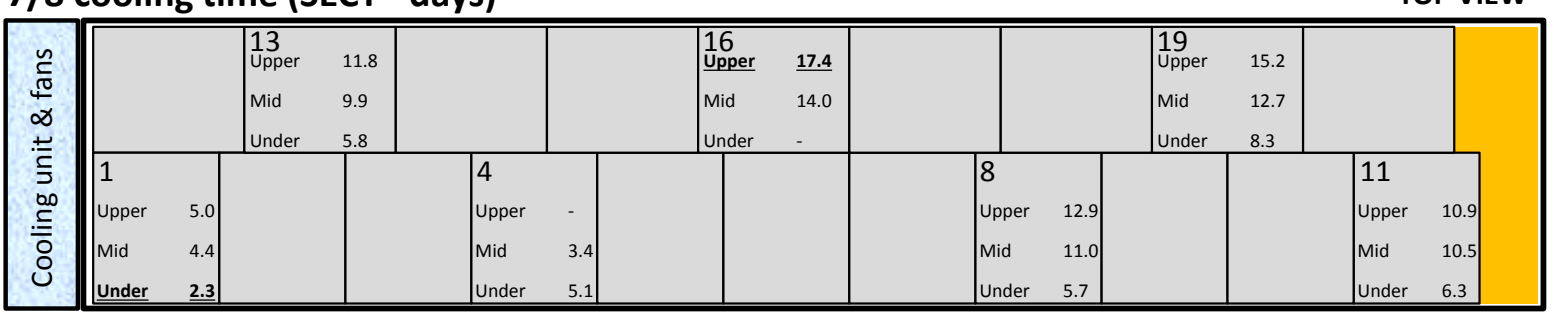

$1 / 2$ cooling time (HCT - days)

TOP VIEW

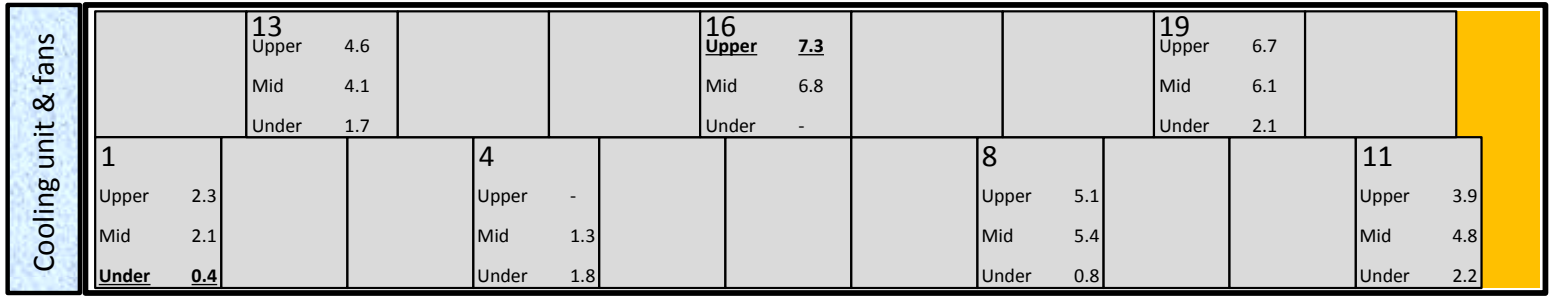

Chilling injury index (0-100)

TOP VIEW

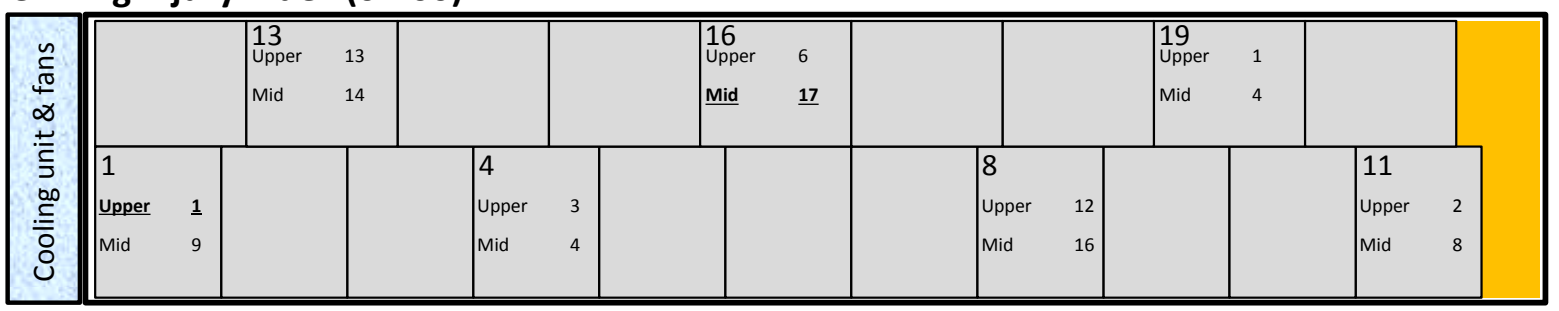

Fig. 5. Seven-eighths cooling time, half cooling time and chilling injury index for different pallets within the container, as a function of height of the box on the pallet (upper, middle or under). Minimum and maximum values are underlined. 